\section{Brainstem tests not adequate to diagnose death in organ donors}

SIR - Your Editorial's call for serious discussion of laws governing the diagnosis of death (Nature 461, 570; 2009) is most welcome, if long overdue. It is imperative that those involved in the practice of transplantation know the status of organ donors. And it is high time that those offering their organs for transplant - "after my death" are the words on NHS Organ Donor Register application forms - are clearly and fairly informed about the state they will be in if their offer is taken up.

In the United Kingdom, 'death' is still being certified for that purpose on the basis of purely bedside tests of some brainstem functions. There has never been sound scientific support for this standard, and it was declared "clinically dangerous" in a report by the US President's Council on Bioethics last year (see go.nature. com/58y3DP).

As you assert, few things are as sensitive as death. Its certain diagnosis is surely of such importance that it should be addressed without concern for dependent interests.

David W. Evans Queens' College, Cambridge CB3 9ET, UK e-mail:dwevansmd@doctors.org.uk

Readers are welcome to join the online discussion about this Editorial at Nature Network, go.nature.com/WjUiku.

\section{Funding on 'Sheriff of Nottingham' model could cut productivity}

SIR - With a view to propelling

Canada to the top tier of international rankings, the presidents of five large Canadian universities have proposed a radical restructuring of postsecondary education. This includes the concentration of research in a few elite universities, with the others focusing on undergraduate education. Predictably, the country's other universities are outraged (see go.nature. com/6MMcsl).

The 'big five' universities (McGill, Montréal, British Columbia, Alberta and Toronto) already receive about $40 \%$ of the country's federal research funding. The 'Sheriff of Nottingham' model - which, like Robin Hood's adversary, robs the poor to pay the rich relies on the premise that productivity increases faster than dollars invested. If this concept is valid, there should be more bang for the buck when funding is concentrated in a few institutions, rather than spread broadly.

Research productivity can be gauged by number of published papers and by the h-index, which measures highly cited publications, although these indicators have their flaws. I calculated both for all the researchers at 27 Canadian universities using data from the ISI Web of Science, based on papers published from 2005 to 2009. I extracted 2009 research funding per university from the three federal granting councils' websites.

According to these two indices, total research productivity and its impact both relate very strongly to the total funding received per university, but both relationships are significantly decelerating. (Details of these calculations are available from the author.) Expressed per dollar invested, research productivity and impact both decrease as funding per university increases. Bang for the research buck is better in smaller institutions.

Concentrating funding in large universities would probably increase their productivity, and perhaps their bragging rights. However, this would come at the price of reduced total research productivity summed over all Canadian universities.
The same conclusion would probably apply to any system in which finite resources for research must be divided among a pool of contenders.

David Currie Biology Department, University of Ottawa, 30 Marie Curie Private, Ottawa, Ontario K1N 6N5, Canada e-mail:david.currie@uottawa.ca

\section{A playful side to twelfth-century mathematics}

SIR - As editors of the book Lilavati's Daughters: The Women Scientists of India, reviewed by Asha Gopinathan (Nature 460, 1082; 2009), we would like to elaborate on the background to its title.

Lilavati was a mathematical treatise of the twelfth century, composed by the mathematician and astronomer Bhaskaracharya (1114-85) - also known as Bhaskara II - who was a teacher of repute and author of several other texts. The name Lilavati, which literally means 'playful', is a surprising title for an early scientific book. Some of the mathematical problems posed in the book are in verse form, and are addressed to a girl, the eponymous Lilavati.

However, there is little real evidence concerning Lilavati's historicity. Tradition holds that she was Bhaskaracharya's daughter and that he wrote the treatise to console her after an accident that left her unable to marry. But this could be a later interpolation, as the idea was first mentioned in a Persian commentary. An alternative view has it that Lilavati was married at an inauspicious time and was widowed shortly afterwards.

Other sources have implied that Lilavati was Bhaskaracharya's wife, or even one of his students — raising the possibility that women in parts of the Indian subcontinent could have participated in higher education as early as eight centuries ago.

However, given that Bhaskara was a poet and pedagogue, it is also possible that he chose to address his mathematical problems to a doe-eyed girl simply as a whimsical and charming literary device.

Ram Ramaswamy Jawaharlal Nehru University, New Delhi 110 067, India e-mail: r.ramaswamy@mail.jnu.ac.in Rohini Godbole Indian Institute of Science, Bangalore 560 012, India

\section{Weighing up NICE against private health-care schemes}

SIR - There is little question that the US health-care system requires reform. But it is debatable whether abdicating personal health-care decisions to an organization like the UK National Institute for Health and Clinical Excellence (NICE), as you recommend in your Editorials (Nature 461, 315-316 and 847; 2009), is the best approach to reform.

NICE decides "which of the available medical options is most effective at treating any given condition". This is beyond reproach and deserving of the international accolades the organization has received. However, NICE also decides "which [medical option] is worth the money". To many Americans, this is objectionable. It is a subjective assessment intimately tied to the individual and shouldn't be in the hands of a committee.

There are myriad reform schemes being debated that still preserve an individual's control over health-care decisions. A poorly implemented private care scheme can always be reformed, but choosing government control means there is no turning back.

Todd A. Gibson University of Colorado Denver, Box 6511, MS 8303, Aurora, Colorado 80045, USA e-mail: todd.gibson@ucdenver.edu

Contributions may be sent to correspondence@nature.com. 